\title{
A revised conceptual model to reproduce the distribution of chlorinated solvents in the Rho aquifer (Italy)
}

\author{
Daniele Pedretti ${ }^{1,2}$, Marco Masetti², Giovanni P. Beretta², and Mariangela Vitiello² \\ ${ }^{1}$ Dept of Geotechnical Engineering and Geosciences, Universitat Politécnica de Catalunya UPC-BarcelonaTech, E- \\ 08034, Barcelona, Spain. E-mail: daniele.pedretti@upc.edu \\ 2 Dipartimento di Scienze della Terra 'A. Desio', Universita degli Studi di Milano, I-20133, Milano, Italy. E-mail: \\ marco.masetti@unimi.it
}

\section{Abstract}

To make cost-effective decisions regarding aquifer protection against chlorinated solvent contamination, a conceptual site model explaining the hydrodynamic behavior of these solvents needs to account for soil heterogeneities in sufficient detail. Among the key requirements, it is necessary to perform site-specific characterization of (a) the architecture and type of chlorinated solvent sources, (b) the architecture, nature and distribution of aquitards (bodies of low permeability) and (c) local groundwater dynamics. Local-scale data are often lacking and regional descriptions are therefore adopted with the consequence of losing small-scale features that control local chlorinated solvent migration which, in turn, limits the effectiveness of safeguard facilities. This paper addresses these arguments, focusing on the Rho aquifer (Italy). We show that the local conceptual model must integrate small-scale architectural and hydrodynamic anomalies of the aquifers and aquitards with regional trends and the sedimentary origin of the aquifers. New evidence are found by processing stratigraphic logs, piezometric heads and solute concentrations from local wells. The conceptual model should account for the occurrence of secondary chlorinated solvent sources located in depressions on the aquitard surface separating the two upper and most contaminated Rho aquifers. While the spatial distribution of depressions is in accordance with regional sedimentological dynamics, the direction of local groundwater flow at various levels within the main hydrogeological unit is remarkably opposite to the regional groundwater tendency. These findings, along with evidence of vertical heterogeneous soil texture and stratification of chlorinated solvents in various phases, are supported by a simple particle tracking model and suggest how to redefine the conceptual model and, consequently, how to design safeguard facilities to effectively prevent further plume spreading. 
Accepted ms - Ground Water Monitoring \& Remediation doi: 10.1111/gwmr.12017

Keywords: conceptual model, chlorinated solvents, heterogeneity, aquitards, secondary sources 1 Introduction

Aquifer pollution by chlorinated solvents represents a serious problem for industrialized countries, due to the high toxicity of these compounds to humans and the high costs of aquifer restoration (Londergan et al 2001, Sale et al 2008, Alberti et al, 2011). In the metropolitan area of Milan (Northern Italy), chlorinated solvents are responsible for more than $50 \%$ of the total solute plumes observed (Provincia di Milano, 2002). When aquifer pollution is detected, pumpand-treat (P\&T) and slurry walls or barrier systems (BS) are commonly combined to promptly prevent the risk of the pollutant spreading to critical receptors in clean zones, such as drinking water supply wells (e.g. Tosco et al 2010).

Decisions regarding the cost-effective use (design and management) of these technologies relies on a conceptual site model (CSM) that represents the origin, migration and degradation of these organic compounds in heterogeneous geological media. The importance of a CSM in remediation and protection efforts against general solute spreading has been widely discussed in the literature (e.g. Konikow and Bredehoeft 1992, Neuman and Wierenga 2003, Refsgaard et al 2006). However, when dealing with chlorinated solvents, developing a reliable CSM is sometimes cumbersome.

Subsurface chlorinated solvents can behave as dense non-aqueous phase liquids (DNAPLs), whose fate in groundwater (Johnson et al 1989, Pankow and Cherry 1996, Chapman and Parker 2005) requires a well-defined CSM that accounts for: (a) origin, type and groundwater dynamics around the (single or multiple) source; (b) identification of the architecture of lowpermeability barriers in terms of lateral and vertical continuity and their hydrodynamic behavior as capillary traps; (c) description of the diffusion process in local low-permeability units and (d) identification of connected and transmissive pathways or distribution of mobile/immobile advection zones that can influence solute transport. The typical lack of aquifer characterization data at adequate scales (such as the source scale) makes identification of ubiquitous soil hydraulic heterogeneities uncertain (e.g., Seifert et al. 2008, Bolster et al. 2009, Suthersan et al, 2010). A CSM relying on regional descriptions or that homogenizes aquifer properties can lead to a misleading design and management of safeguard and remediation strategies, with important economic and environmental losses. 
Accepted ms - Ground Water Monitoring \& Remediation doi: 10.1111/gwmr.12017

Over the last 30 years, a wide chlorinated solvent plume has developed in the Rho aquifer of Northern Italy and has migrated several kilometers downstream threatening public drinking wells close to Milan (Provincia di Milano 2002) (fig.1) The origin of the pollution is poorly characterized and an inefficient slurry wall barrier system (BS) was used to confine the initial source area. In addition to that, a pump-and-treat system (P\&T) was installed to help reducing the concentration levels of chlorinated solvents. but with scarce effectiveness, according to the results of the recent monitoring activities showing anomalous chlorinated solvent concentrations in several piezometers located downgradient the P\&T

The aim of this paper is to show how the data and methodologies from a variety of subsurface disciplines allow the CSM to be revised to account for the existence of secondary contaminant source areas and the uncertain direction of local groundwater flow. One of the key points is represented by the uncertain current position of some of the DNAPLs. While an initial source area was identified more than 30 years ago, both the inefficiency of the local BS (Pedretti et al 2012), and the possible gravity driven migration along the top of capillary barriers suggest the existence of a secondary source zone. To support our hypothesis, we include the local sedimentary origin of the area using morphological mapping of the aquitard surface to highlight potential preferential DNAPL migration pathways. A numerical flow model coupled with a particle tracking algorithm was developed to infer qualitative information relating to the initial source of chlorinated solvent plumes.

Section 2 offers a brief introduction of the site and highlights discoveries during monitoring activities that contrast with the initial CSM used to design the local remediation systems. Section 3 describes the specific characterization activities carried out to evaluate geological conditions, groundwater flow patterns and the dissolved phase at a local scale. In Section 4 a revised CSM is proposed and supported by numerical groundwater flow and particle tracking simulations.

\section{Site description}

In this Section, we first describe the geological and hydrogeological setting by using regional stratigraphic descriptions and considering the geological processes that occurred at the site; we then observe the difference between local and regional geological features. Finally, we describe the main evidence and the spatio-temporal evolution of contamination patterns recorded after significant monitoring activity at the site.

\subsection{Geological and hydrogeological setting}


Accepted ms - Ground Water Monitoring \& Remediation doi: 10.1111/gwmr.12017

The spatial distribution, relative proportion and continuity of deposits all determine groundwater flow and contaminant transport in alluvial aquifers (Koltermann and Gorelick 1996). In general, alluvial facies consist of randomly distributed and inter-connected coarse-grained materials, originating from paleostreams, surrounded by a fine-grained matrix which is characterized by lower transmissivity. When glacial events occur, glacio-fluvial deposits, such as those originating during the Pleistocene age over the whole of the Southern Alps (Bini et al. 2004), including Rho, consist of a sudden transition from coarse (aquifer) to fine (aquitard) materials. Under certain circumstances, the latter are organized as pedogenetic soils, whose characteristic patterns, such as clay content and geochemical composition, depend on the prevailing climate at the time of formation and on local geodynamic conditions.

An important factor to consider in glacio-fluvial systems is the presence of superficial water streams originating from glacial meltwater. The scouring effect of streams on paleosoils determines local and abrupt lateral transitions from silty clay to sandy gravel materials on these horizons. Such horizon 'windows' are characterized by a localized, higher hydraulic conductivity than the rest of the paleosoils. Therefore, the apparent continuity of both connected coarse materials and aquitards depends on the scale of the characterization, and thus influences the way contaminant transport is modeled at the scale of interest.

In the case of DNAPL contamination in glacio-fluvial aquifers, identifying preferential flow windows and topographic gradients on the capillary barrier surface is fundamental to understanding and predicting DNAPL transport pathways and to make appropriate decisions regarding remediation activities. Characterizing aquifer and aquitard heterogeneities is nonetheless cumbersome. The main reason for this is that the spatial resolution of typical characterization surveys is much coarser than the scale at which lateral transitions occur and too little information exists to obtain a reliable aquitard surface map. The Rho case illustrates how insufficient geological characterization can lead to a CSM inaccurately describing both the origin and distribution of chlorinated solvents.

At a regional scale, the Rho aquifer can be seen as a multilayered system of four well-defined hydrogeological units (Fig. 2). The upper unit, $A$, is the most vulnerable to surface-originated pollution in the Milan area (Masetti et al. 2009). Aquifer $A$ is divided into A0, A1 and A2, which are each separated by aquitards. The upper A0/A1 aquitard is located at a depth of approximately $9 \mathrm{~m}$ below the surface and is where the BS has, supposedly, been keyed (Pedretti et al 2012). The A1/A2 aquitard is deeper at approximately $30 \mathrm{~m}$. The lower limit of A2 occurs at approximately $45 \mathrm{~m}$ below the surface. 
Accepted ms - Ground Water Monitoring \& Remediation doi: 10.1111/gwmr.12017

Fig. 2 (a) shows a hydrogeological cross-section below the Rho area, inferred from the correlation of three types of materials (coarse, medium and fine) that were observed at different depths during well drilling. At this scale the A0/A1 and A1/A2 aquitards apparently show lateral continuity across the study area with similar average thickness (about 1-1.5 m), dip direction (toward NNW-SSE) and topographic gradient $(0.2-0.3 \%)$. No apparent texture heterogeneity can be defined for the aquifers from this information. According to the Provincia di Milano (2002) and ENI AGIP (2003), the aquitard extension continues across the entire study area.

Using more detailed spatial information from well stratigraphy, local scale heterogeneities become more evident. The hydrogeological profile showed in Fig. 2 (b), shows that the A0/A1 aquitard is locally discontinuous. More specifically, we show that (a) lateral transitions may occur from silty clay to sandy materials along the aquitard, (e.g. at the highlighted point in Fig. 2) and (b) the contact surface of the upper aquifer $\mathrm{A} 0$ with the aquitard is irregular, forming a series of topographical highs and lows which can affect DNAPL movement. Hereafter we refer to the contact surface between the $\mathrm{A} 0$ aquifer and the $\mathrm{A} 0 / \mathrm{A} 1$ aquitard as the 'A0 base'.

\subsection{Evidence of contamination and initial remediation measures}

Since 1979, trichloroethene (TCE), tetrachloroethene (TeCA) and other types of chlorinated solvents have continuously been monitored in groundwater with concentrations higher than the regulatory limits which, in Italy, are 1.5 and 0.05 micrograms per liter of drinking water for TCE and TeCA respectively (G.U. Repubblica Italiana 2006). Table A (supplementary online materials) reports most of the data collected from the site since 1979. Monitoring equipment includes both small diameter $(10 \mathrm{~cm})$ piezometers, and medium diameter $(40 \mathrm{~cm})$ wells, hereafter identified by the prefix ' $p z$ ' and ' $w$ ' respectively; the latter were also used for well tests. We also distinguish between (Superficial) S-boreholes and (Deep) D-boreholes:

- S-boreholes were drilled in the $\mathrm{A} 0$ aquifer up to a mean depth of 9-10 m and were screened along the entire vertical borehole column;

- D- boreholes were drilled in the A1 aquifer up to 30-32 m in depth and were screened from 12$15 \mathrm{~m}$ to $30-32 \mathrm{~m}$,

A third type of borehole, B-type, consists of wells drilled up to $70 \mathrm{~m}$ in depth; these points did not provide information regarding chlorinated solvent contamination for this study.

As an initial attempt to control the plume from spreading, a slurry wall barrier was installed in 1982 to isolate a small volume of the upper $\mathrm{A} 0$ aquifer covering a superficial area of $625 \mathrm{~m}^{2}$ with an average depth of $9 \mathrm{~m}$ (Pedretti et al 2012). The location was chosen on the basis of an initial random characterization of the site which identified concentrations of chlorinated solvents in $\mathrm{pz}$ 
Accepted ms - Ground Water Monitoring \& Remediation doi: 10.1111/gwmr.12017

672 exceeding $1 \mathrm{mg} / \mathrm{L}$. Both the reliability and design of this BS barrier have always been questioned (Pedretti et al , 2012)). In 2006 a hydraulic barrier was designed downstream of the BS comprising 15 wells (Fig. 3), four of which were screened in the A1 aquifer (D-borehole) while the remaining eleven were screened in the A0 aquifer (S-borehole). Only w 686 and w 789 in the A1 aquifer have been used since 2010 to contain the chlorinated solvent plume.

\subsection{Initial conceptual model}

As shown on Fig. 3, both the P\&T wells and the majority of the existing $A 0$ and $A 1$ boreholes were drilled along a NW-SE axis, which is collinear with the regional flow and plume direction (fig. 1). With the exception of $w 686$, the P\&T wells are located in the south western section of the domain. These wells are also perfectly aligned with the initial source of DNAPLs identified in the BS area. This specific selection of P\&T wells was likely based on four main assumptions of the CSM model that describe the distribution of pollutants in the local subsurface:

(1) the top portion of aquifer (A) was expected to be clearly divided into two well-defined and hydraulically independent aquifers, with similar hydraulic behavior to that found in the regional descriptions. This is confirmed by the existence of two distinct borehole categories related to screening depth (S- and D-types);

(2) the $A 0$ and $A 1$ aquifers were expected to show the same mean groundwater flow direction (NW-SE axis), similar to the regional trend;

(3) hydraulic separation was associated with the A0/A1 aquitard, considered as a continuous and impermeable capillary barrier with lateral extension covering the entire Rho site; and (4) the slurry wall area was considered as the only contaminant source zone.

There are, nonetheless, several aspects that do not fit the initial CSM model, particularly when considering the recently observed distribution of solute concentrations. Fig. 4 represents a map of normalized (log) concentrations of TCE versus TeCA, for S-type (left panel) and D-type (right panel) boreholes observed in June 2007 (Table A, supplementary online material). In the S-type boreholes the TCE/TeCA ratio is almost uniform and TCE is lower than TeCA $(T C E / T e C A<1)$. This distribution is much more heterogeneous, however, in the D-type boreholes; pz.663, pz.348, pz.346 and pz.689 in particular display the presence of higher TCE/TeCA ratios than other locations. The spatial distribution of the highest TCE/TeCA appears to follow a N-S direction, rather than the expected NE-SW orientation followed by the majority of boreholes in the area and by the regional groundwater flow. Moreover, Fig. 4 shows that the very low ratio at pz.664 $(\mathrm{TCE} / \mathrm{TeCA}=0.05)$ appears to be anomalous as its two closest boreholes, pz.346 and 
pz.663, both display a much higher ratio (TCE/TeCA $=4.98$ and 16.35 respectively), indicating high variability of solute behavior. A revised conceptual model should therefore consider the following aspects:

1 The possibility that additional sources of TCE and TeCA, in addition to those within the BS encapsulated area, may exist which would help explain the distribution of solutes.

2 Heterogeneous distribution of connectivity and hydraulic conductivity can generate preferential flow paths that control solute migration within the A1 aquifer, potentially affecting specific boreholes, thereby causing anomalous concentrations.

3 Groundwater flow dynamics occurring at the site scale may be very different from regional dynamics due to the existence of hydraulic heterogeneities. It is important to consider that aquifers can display different responses to recharge, behaving A0 aquifer as an unconfined unit, and $\mathrm{A} 1$ aquifer as a (semi)confined unit.

4 Aquitard A0/A1 may be irregular in shape and thickness due to its glacio-fluvial origin and the possible successive formation of paleosoils. Along the erosional paths, DNAPLs could have moved under gravity and via the aquitard window resulting in DNAPL mass in the deeper aquifer zones.

3. Specific activities between 2006 and 2008

\subsection{Aquitard geometry}

Our hypothesis is that additional sources of chlorinated solvents may exist within the area. One explanation for such additional sources is that DNAPLs could have migrated during the last 30 years due to gravitational forces on top of the A0/A1 aquitard, thus forming a secondary source, distributed along this pathway, potentially impacting the $\mathrm{A} 1$ aquifer below..

The topography of the A0 base using a kriging with trend method (e.g., Gooverts, 1997) is shown in Fig. 4 (a). Stratigraphic information was inferred from the drilling logs of the $S$, D, and $B$ boreholes. The trend given to the topographical regional gradient is similar to those found in regional studies (ENI-AGIP, 2002). The variogram analysis on the residuals (i.e., the difference between measured value and trend value at each location) reveals that the residuals are highly correlated in the NNE-SSW direction, which corresponds to the main direction of scouring and erosion activity by the glacial-originating streams (Bini et al, 2004). A variogram map of the residuals is shown in Fig. A (supplementary on line material). 
Accepted ms - Ground Water Monitoring \& Remediation doi: 10.1111/gwmr.12017

The A0 base is shown on Fig. 4(a) together with the relative proportion of solute concentrations. The source area is located on a topographical peak on the AO surface, as indicated by the arrows (representing the topographical gradients of the surface) diverging in all directions. Among the steepest paths, the main focus is on the steepest gradient, which is directed from the source area towards the south west (pz.349, pz. 600 and pz.599) and is relevant in the discussion below.

\subsection{Analysis of bulk soil concentration and aquitard clay composition}

Most of the analyses performed in the Rho aquifer were performed to monitor chlorinated solvents in the solute phase. However less attention was posed to address the distribution of these organic compounds in other phases, such as the bulk soil concentration,, which can also give important details about the distribution of the pollutants in the area. For this purpose, and to improve the site characterization with additional information about grain size distribution and clay content of aquitards, the drilling cores of the NG1 piezometers (drilled in 2007) were sampled and analyzed.

The stratigraphic analysis revealed that in this location two fine-grained horizons exist at a 10 to $12 \mathrm{~m}$ depth (attributable to the A0/A1 aquitard) and at a 29 to $35 \mathrm{~m}$ depth (attributable to A1/A2), respectively. As shown in Fig. B (supplementary online material), SP indicates the locations of six soil samples collected from the drilling core. Sieving analysis indicated that, at the level of the A0/A1 aquitard (second SP from the top, at about $10 \mathrm{~m}$ ), silt is the dominant soil material and the clay content is around 15-20\%. In the A1/A2 aquitard, the dominant grain size of soils collected at both the top (about $30 \mathrm{~m}$ ) and at the bottom (about $35 \mathrm{~m}$ ) of the aquitard is sand. Analysis showed that no gravel is present at the bottom of the A1/A2 aquitard. Different proportions of grain size were also observed at the other SP samples, indicating vertical heterogeneities in the sedimentary footprint.

The bulk soil concentration of different chlorinated compounds were also determined from the NG1 core samples (right of fig. B). Results indicate that chlorinated solvents are heterogeneously stratified in this point of the aquifer; in this case, the peaks of total solute concentrations (circles) occur at depths of 5,30 and $35 \mathrm{~m}$. A peak of TCE was observed at the top of the aquitard A1/A2, while no significant TCE content was observed at the bottom of this aquitard. Peaks of TeCA were found at a $35 \mathrm{~m}$ depth at the bottom of the A1/A2 aquitard, and just below the upper A0/A1 aquitard (15 m depth). Large amounts of other chlorinated 
Accepted ms - Ground Water Monitoring \& Remediation doi: 10.1111/gwmr.12017

compounds were also found in bulk soil concentration, particularly between 35 and $45 \mathrm{~m}$ in depth. For example, high concentrations of 1,1,1-trichloroethane (TCA) were found in aquifer A2 and also in the shallower portions of the A0 aquifer. High concentrations of 1,1-Dichloroethene (DCE), in both isomeric forms trans-DCE (tDCE) and cis-DCE (cDCE), were found in the shallower horizons $(5 \mathrm{~m})$ and also at greater depths (35 to $45 \mathrm{~m}$ ). All the results of the chemical analysis are listed in Table $A$ (supplementary material)

These results indicate that: (1) monitoring of chlorinated solvents in A2 is needed for further characterization; (2), important parent-daughter chain reactions should be accounted for in order to more clearly understand chlorinated solvent dynamics; and (3) gravity driven migration of chlorinated solvents through the A0/A1 aquitard is probably responsible of the high bulk soil concentration found at the bottom of the $\mathrm{A} 1$ aquifer.

Moreover, the larger amount of clay in A0/A1 compared to A1/A2 indicates that these two horizons have a different sedimentary origin, with the upper aquitard potentially having developed as a paleosoil.

To determine the sedimentary origin of these horizons, we analyzed the relative proportions of mineral content in each SP sample using diffractometer analyses. For the upper aquitard A0/A1, it was apparent that illites are the prevalent clay mineral with other phyllosilicates, such as chlorite and smectite, found in lower amounts. In the A1/A2 aquitard, the composition was more homogeneous, with potassium phyllosilicates prevailing over other clay minerals. The presence of illite, smectite and chlorite in A0/A1 is an indicator of paleosoil development as these minerals particularly develop in warm environments, such as during interglacial periods.

The sedimentary origin of the A0/A1 horizon is relevant for the geostatistical reconstruction of the $\mathrm{A} 0$ base. It suggests that the structures represented by the variogram analysis are most likely erosional pathways that originated from glacial streams in the paleosoil, thus supporting the theory of potential migration paths for DNAPLs.

\subsection{Piezometric surfaces}

Piezometric surfaces were also built using a kriging method to account for local trends in the data: S-wells and D-wells were used for $A 0$ and $A 1$ aquifers respectively. For both aquifers, the variogram analysis of the piezometric data revealed that there was no correlation between the residuals (i.e. they were randomly distributed); as such residuals have been studied using a deterministic interpolator.

We studied the hydraulic head evolution over a three years period and the key findings of this analysis are listed as follows. 
Accepted ms - Ground Water Monitoring \& Remediation doi: 10.1111/gwmr.12017

The mean direction of groundwater flow in the A0 aquifer was found to be similar to the regional groundwater trend (oriented NW-SE, see Fig. 1) and to the mean depositional direction of the geological units, while the mean flow direction in A1 follows a NE-SW direction (Fig. 4(b)). This general difference between the flow directions was maintained, with limited changes, over time; In each aquifer unit, however, the flow directions consistently change over time following a seasonal periodicity. From summer time (low rain season in the Milan area) to winter time (high rain season), the mean flow direction in the A0 aquifer rotates between NNW-SSE and WNWESE, while in the A1 aquifer it rotates between NNE-SSW and ENE-WNW. Such evolution can be associated with the higher recharge in the winter time and lower recharge in the summer, affecting the head levels in both aquifers. In the A1 aquifer, for instance, the flow direction NNE_SSW occurs when the aquifer is in confined conditions during the high rain season while the ENE-WNW flow direction prevails in the low rain season when the aquifer is almost unconfined or semiconfined.

Despite this seasonal variation in groundwater flow patterns, when comparing the piezometric gradients (gray arrows) with the solute distribution from the D-wells in Aquifer A1 (Fig. 4(b)), it can be seen that the highest concentrations of TCE versus TeCA (especially at pz.346 and pz.669) can not be explained by only considering a source located at the BS zones.

\section{Testing a new conceptual model}

With the additional data, several new key need to be considered for an adequate representation of the chlorinated solvent dynamics in the Rho aquifer, specifically: a) evidence of irregular architecture of the A0/A1 aquitard surface, b) high concentration of solutes in both bulk soil and solute concentration, c) the time dependency of groundwater direction (possibly as a function of the seasonal fluctuation of recharge) and d) the existence of vertical solute stratification. This evidences make clear that the assumption of homogeneously-distributed hydraulic properties of the aquifer, lateral continuity of capillary barriers and a unique source of contamination should be updated to include more complex information.

In particular, the new CSM should integrate the following key aspects.

- The possible migration of DNAPLs by gravity along the steepest topographic gradients of the top surface of the A0/A1 aquitard. Despite these movements are particularly slow, it should be considered that the first evidence of site contamination were detected in 1980's (Provincia di 
Accepted ms - Ground Water Monitoring \& Remediation doi: 10.1111/gwmr.12017

Milano, 2002). Since then no effective remediation efforts have been taken on sources to prevent the spreading of contamination.

- The existence of pools of DNAPLs that can be lying in stagnant areas on the top of the aquitard. This is in relation with the irregular surface of the aquitard. These areas can have a strategic role as secondary areas releasing solutes into the A1 aquifer, as shown in $\S 3.1$;

- the different mean groundwater flow direction between $A 0$ and $A 1$, analyzed in $\S 3.3$, which are also subject to fluctuations due to seasonal recharge conditions;

- the existence of both vertical and horizontal heterogeneities in the hyrogeological structure, which generate preferential and stratified solute migration within the aquifer units, as shown in $\S$ 3.2..

The combination of these hypotheses could, potentially, explain the TCE peaks at pz.663, pz.348, pz.346 and pz.789 (which display higher TCE/TeCA rations than other points). While testing all the possible scenarios would be very complex, we chose to focus on the potential role that the non-uniform distribution of the aquitard geometry might play as a secondary contaminant source into the local aquifer. For this purpose, particle-tracking analysis has been coupled with a groundwater 3D model to test different TCE contaminant pathways into the A1 aquifer (which should form a well-defined plume in the central portion of the A1 domain, as suggested by the distribution of concentration peaks - see Table A, supplementary online material, and fig. 4). The details about the numerical codes, model setup and its calibration are provided in the supplementary material.

To test our hypothesis, we developed the following scenarios (fig. 5):

- Scenario A focuses on the existence of a well-defined source of contamination within the encapsulated area in the A0 aquifer. A numerical simulation was then built by positioning the particles within the first layer of the model, within BS.

- Scenario B simulates the existence of an additional source, located on the right of the encapsulated area in aquifer A1 and, specifically, below a potential DNAPL migration path from the encapsulated zone in $\mathrm{A} 0$ along the steepest gradients of the A0/A1 aquitard, roughly oriented NW-SE. To model this scenario, particle sources are located in the third model layer and at the cells that correspond to the position of the steepest gradients in the aquitard. . This scenario takes into account the first key aspect of the new CSM reported above.

- In Scenario B, two versions were considered with wells 686 and 789 either non-active (B1) or active (B2). Fig. 5 shows that the elongated marked area only approximately indicates where 
Accepted ms - Ground Water Monitoring \& Remediation doi: 10.1111/gwmr.12017

DNAPLs could have moved along the A0-A1 aquitard surface; an exact determination of DNAPL distribution is not possible with the available information.

The results show that Scenario $A$ is unlikely since the particles sink into aquifer $A 1$ from the bottom of the encapsulated zone and are carried (by advection) too far from any of the boreholes in the area with highest solute concentrations. Scenario B1 is also unlikely as particles travel towards both contaminated boreholes and clean boreholes within the area. For example (see Table A, supplementary online material), concentrations at pz.NG2 and pz.351 were much lower than those observed at pz.669 or pz.348. Scenario B2 offers a more likely situation where the well capture zone influences particle pathways, which converge towards the well and limit the plume size to a more restricted and well-defined area within the central portion of the domain. In this case, particles do not travel toward pz.NG2 and pz.351.

\section{Conclusions}

An accurate characterization of the hydrodynamic and geological background, along with numerical simulations of the groundwater dynamics, has been used to reformulate the conceptual model that describes the actual origin and migration of chlorinated solvents at the Rho site. Based on field evidence from the latest monitoring activities, the initial postulation of a well-defined, unique source of contamination of the local aquifers by chlorinated solvents has been demonstrated to be poorly representative and, at the present time, is insufficient to explain the distribution of these compounds in solute form. In addition, soil hydraulic parameters and piezometry were found to follow regional patterns which hide the small-scale heterogeneities that control the migration of solutes from this site.

A new conceptual model has been formulated in this paper. The new hypothesis accounts for additional secondary sources of contamination, identifiable by means of detailed maps of the aquitard topography. It is supposed that chlorinated solvents possibly migrated in non-aqueous form (i.e. as DNAPLs) on top of the upper aquitard, and from there they act as secondary contaminant sources areas. Once they pass through the aquitard, by diffusion or direct contact between aquifers, chlorinated solvents spread into the bottom aquifer in the form of solutes where the aquitard lakes become eroded by paleostreams. It should be noted that this scenario is only possible if the main contaminant source has been active since 1960. These hypotheses are partially supported by direct measurements and by means of numerical simulation of flow dynamics.

Exploratory particle tracking analysis indicates that considering more than one source, and specifically one extending from the main source along the steepest section of the A0/A1 
aquitard surface (fig. 3a), explains the migrating paths of solutes towards the piezometers, where chlorinated solvents have been measured in the highest concentrations. A scenario with a unique contamination source cannot explain this behavior.

These results allowed us to obtain semi-quantitative information that can be used to update existing remediation strategies for cost-effective solutions to the problem of chlorinated solvent contamination within the Rho site.

\section{Acknowledgments}

We acknowledge the financial support of the Italian Ministry of Education, University and Research (MIUR) through the PRIN-2005083418-001 Project, and the project partner Dipartimento di Chimica, Sapienza-Universita' di Roma.

\section{Bibliography}

Alberti L., Lombi S., Zanini A. (2011): "Identifying sources of chlorinated aliphatic hydrocarbons in a residential area in Italy using the integral pumping test method" Hydrogeology Journal Volume 19, Number 6, pp. 1253-1267

Allen-King, R.M., Groenevelt, H., Warren, C.J., Mackay, D.M.: Non-linear chlorinated-solvent sorption in four aquitards. Journal of Contaminant Hydrology 22(3-4) (1996) $203-221$

Bini, A., Zuccoli, L., Bussolini, C., Corbari, D., Rold, O.D., Ferliga, C., Rossi, S., Viviani, C.: Glacial history of the southern side of the Central Alps, Italy. In Ehlers, J., Gibbard, P., eds.: Quaternary Glaciations Extent and Chronology - Part I: Europe. Volume 2, Part 1 of Developments in Quaternary Science. Elsevier (2004) 195 - 200

Bolster, D., Barahona-Palomo, M., Dentz, M., Garcia, D.F., Sanchez-Vila, X., Trinchero, P., Valhondo, C., Tartakovsky, D.M.: Probabilistic risk assessment applied to contamination scenarios in porous media. Water Resour. Res. 45 (2009) W06413, doi:10.1029/2008WR007551 
Accepted ms - Ground Water Monitoring \& Remediation doi: 10.1111/gwmr.12017

Cervini-Silva, J., Larson, R.A., Wu, J., Stucki, J.W.: Estimation of interfacial tension between organic liquids and water. Environ. Sci. Technol. 35(12) (2001) 805-809

ENI-AGIP and Regione Lombardia Geologia degli acquiferi padani della Regione Lombardia. Technical report. Regione Lombardia - ENI Divisione AGIP (2002)

Gazzetta Ufficiale della Repubblica Italiana, Art. 152/2006

Gooverts, P.: Geostatistics for environmental applications. Oxford University Press, USA (1997)

Harbaugh, A., Banta, E., Hill, M.C., McDonald, M.G. Modflow-2000, the U.S.Geological Survey modular ground-water model - user guide to modularization concepts and the ground-water flow process. Technical report, U.S. Geological Survey Open-File Report 00-92 (2000)

Konikow L F and Brefehoeft, J D, 'Groundwater models cannot be validated', Advances in Water Resources, 15(1), (1992). 75-83

Koltermann, C E and Gorelick, S 'Heterogeneity in sedimentary deposits: A review of structureimitating, process-imitating, and descriptive approaches', Water Resources Research, 32 (9) (1996) 2617-2658.

Londergan, J.T., Meinardus, H.W., Mariner, P.E., Jackson, R.E., Brown, C.L., Dwarakanath, V., Pope, G.A., Ginn, J.S., Taffinder, S.: DNAPL removal from a heterogeneous alluvial aquifer by surfactant-enhanced aquifer remediation. Ground Water Monitoring \& Remediation 21 (2001) $57-67$

Masetti, M., Sterlacchini, S., Ballabio, C., Sorichetta, A., Poli, S.: Influence of threshold value in the use of statistical methods for groundwater vulnerability assessment. Science of The Total Environment 407(12) (2009) 3836 - 3846.

Neuman S P and Wierenga, P J 'Comprehensive Strategy of Hydrogeologic Modeling and Uncertainty Analysis for Nuclear Facilities and Sites',Technical Note, Office of Nuclear Regulatory Research,U. S. Nuclear Regulatory Commission,Washington, DC 205550001 (2003) 
Pollock, DW User's Guide for MODPATH/MODPATH-PLOT, Version 3: A Particle Tracking Post-processing Package for MODFLOW. Technical report, U.S. Geological Survey Open-File Report 94-464 (1994)

Refsgaard J C, van der Sluijs J P, Brown J, van der Keur P 'Framework for dealing with uncertainty due to model structure error', Advances in Water Resources 29 (2006) 1586-1597

Sale, T., Newell C., Stroo, H., Hinchee, R., Johnson, P. Frequently Asked Questions Regarding Management of Chlorinated Solvent in Soils and Groundwater. Developed for the Environmental Security Testing and Certification Program (ER-0530), US (2008)

Sale, T., Zimbron, J., , Dand, D. Effects of reduced contaminant loading on downgradient water quality in an idealized two layer system. J Contam Hydrol 102 (2008) 72-85

Seifert, D. Sonnenborg, T.O., Scharling, P. and Hinsby, K. Use of alternative conceptual models to assess the impact of a buried valley on groundwater vulnerability. Hydrogeology Journal 16 (4) (2008 ) 659-674

Suthersan, S.,Horst, J., Nelson, D., Potter, S. : Aquifer tuning for optimum performance of InSitu remedies. Ground Water Monitoring \& Remediation 30 (2) (2010) 3944

Vassena, C., Cattaneo, L., Giudici, M.: Assessment of the role of facies heterogeneity at the fine scale by numerical transport experiments and connectivity indicators. Hydrogeology Journal 18 (2010) 651-668 doi: 10.1007/s10040-009-0523-2.

Velde, B.: Clay minerals. a physico-chemical explanation of their occurrence. Developments in Sedimentology 40 (1985) 427 
Accepted ms - Ground Water Monitoring \& Remediation doi: 10.1111/gwmr.12017

\section{Figure captions}

Figure 1: Map of the North Western part of the Province of Milan. Contour lines indicate the main regional head contours of aquifer A. Modified from Provincia di Milano (2002).

Figure 2 Two hydrogeological profiles of the North-Western part of the Milan province, at two different scales for the Rho site: (a) a regional description indicates that aquitards have long lateral continuity and aquifers are homogenized; this is obtained by linearly interpolating information from vertical logs; (b) at a more local scale some discontinuity zones are evident by observing lateral transitions from finer to coarser grain size deposits in the aquitards.

Figure 3 Map of wells and piezometers in the Rho area. Single starred points indicate P\&T wells. Blue crosses indicate piezometers set up to control the P\&T. The border line surrounding the source area also represents the position of the slurry wall.

Figure 4 Relative proportion of TCE versus TeCA monitored on June 2007 at several locations in the (a) A0 and (b) A1 aquifers. Symbols are scaled according to the (log) values. In (a) the A0/A1 aquitard topography is also shown (along with gradient vectors) and in (b) the piezometric surface for the A1 aquifer in April 2007 (and relative gradient vectors) are shown.

Figure 5 Conceptual models (above) and particle tracking results (below) for three scenarios describing the transport of solute in the A1 aquifer depending on the position of the source: (a) a source is simulated only within the encapsulated zone in A0, and no wells are active. ; (b) part of the aquitard located just below the steepest gradients of the aquitard surface is also considered as an additional source of solute, and no wells are active; and (c) the same conceptual model as (b) is adopted and w.686 and w.789 are now active extraction wells. 


\section{Supplementary online material}

Figure A Variogram map of the residuals for the $\mathrm{A} 0$ surface. The arrow indicates the direction of maximum correlation (NE-SW), which is consistent with the geological origin of paleostreams in the area.

Figure B Results of the grain size activities (left side of the column) and analysis of total contaminant (right) performed on six soil samples (SP) collected at different depths during the borehole drilling of pz.NG-1. For graphical reasons, contaminants tags on the right have been omitted, and for concentrations lower than $10 \mathrm{mg} / \mathrm{kg}$, the size of the box has been exaggerated.

\section{SUPPLEMENTARY MATERIAL}

\section{MODEL:}

The groundwater flow model was developed using the finite-differences code MODFLOW (Harbaugh et al, 2000) in three dimensions in order to better reproduce the exchange dynamics between the hydrogeological units. Layers represent aquifers A0 (Layer 1) and A1 (Layer 3) and the A0/A1 aquitard lying between them (Layer 2). The geostatistical map of the aquitard surface in fig. 3a was used as the top surface of Layer 2, while the bottom surface was obtained by deterministic interpolation (inverse distance method) of well logs. Laterally, each layer accounts for an area of $500 \times 500 \mathrm{~m}$, with telescopic mesh refinement used towards the center of the domain. The finest cell size is $1 \mathrm{~m}^{2}$, gradually increasing towards the lateral boundaries by a factor of up to 1.2. Aquifer A0 was modeled using unconfined conditions, while aquifer A1 was allowed to change between confined and unconfined conditions. Cauchy boundary conditions were applied on the northern and southern boundaries of $A 1$, no-flow conditions were simulated for the eastern and western boundaries. The calibration was performed against the groundwater heads measured in April 2007. Wells w.686 and w.789 were simulated to be active in Aquifer A1 for a time period long enough to consider the groundwater level to be in a steady state condition. 
The calibration was performed by minimizing differences between observed and calculated heads in a trial-and-error approach achieved by adjusting different sets of model parameters. This process resulted in six homogeneous zones of hydraulic conductivities ranging from $10^{-5}$ $\mathrm{m} / \mathrm{s}$ to $10^{-3} \mathrm{~m} / \mathrm{s}$. In particular, the higher hydraulic conductivity zone was set in the central area; the goodness of fit supports the hypothesis of a preferential path existing in the subsurface that affects groundwater flow and solute transport.

A particle tracking solution was coupled to the groundwater flow solution using MODPATH (Pollock, 1994) in order to track the advective paths of solute spreading from selected locations in the $\mathrm{A} 1$ aquifer. 


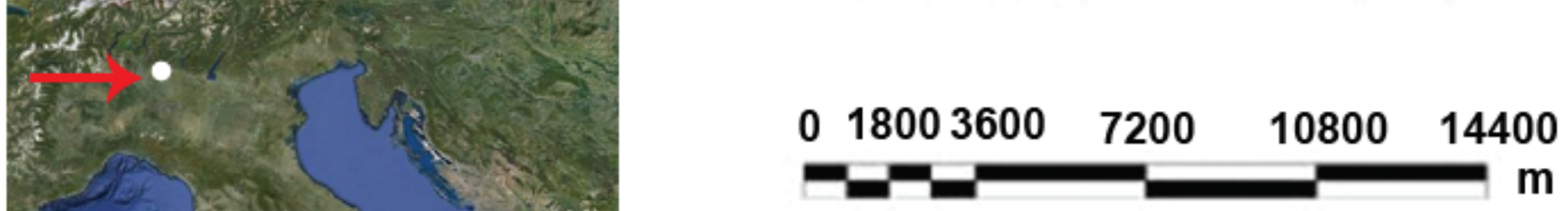

\section{Legend:}

Head contour (m asl)

Streams

Groundwater depth (m)

$0 \mathrm{~m}$

0-5 m

5-10 m

10-15 m

15-20 m

20-30 m

30-40 m

$>40 \mathrm{~m}$

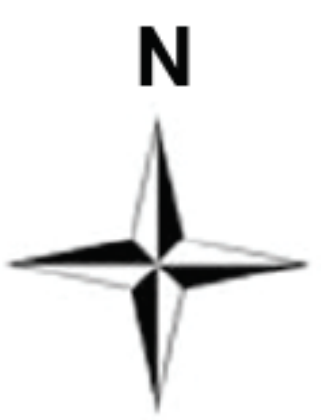




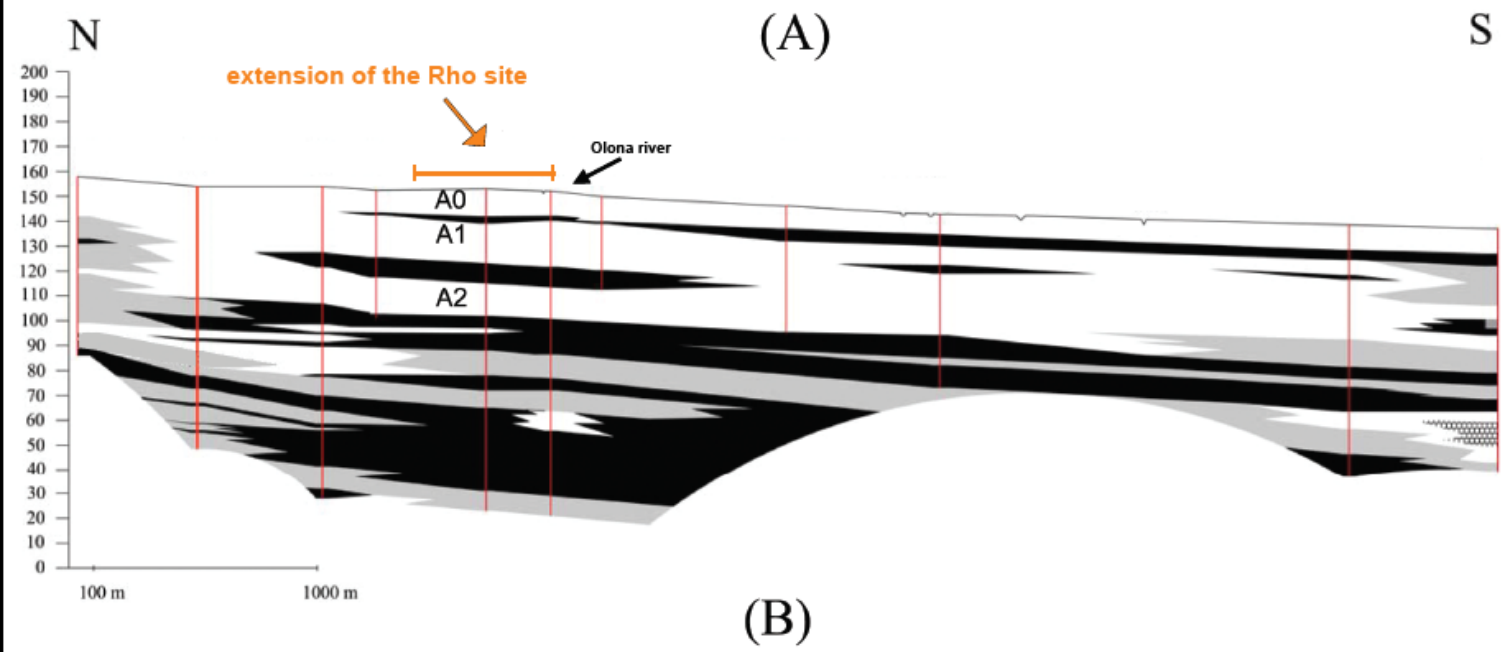

meters a.s.l.

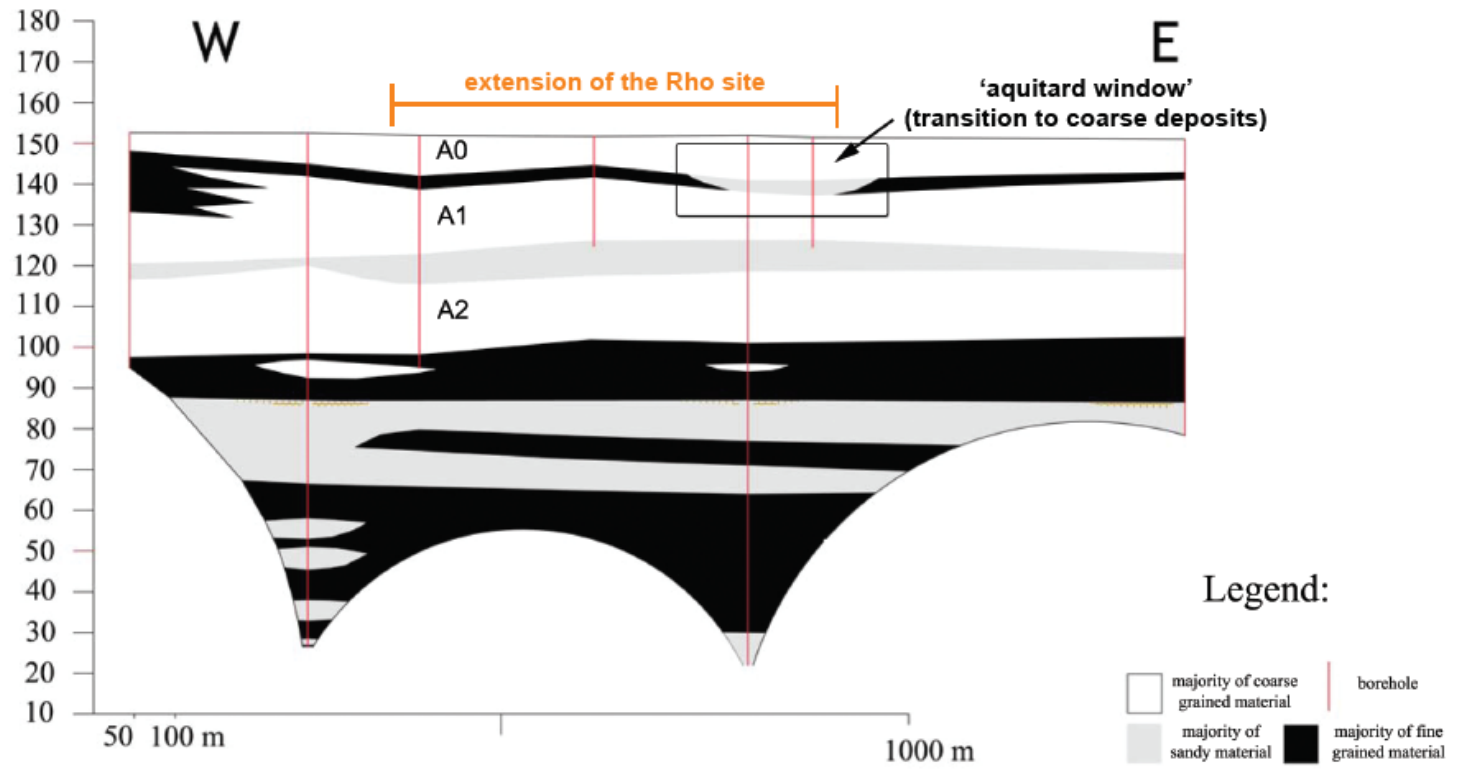




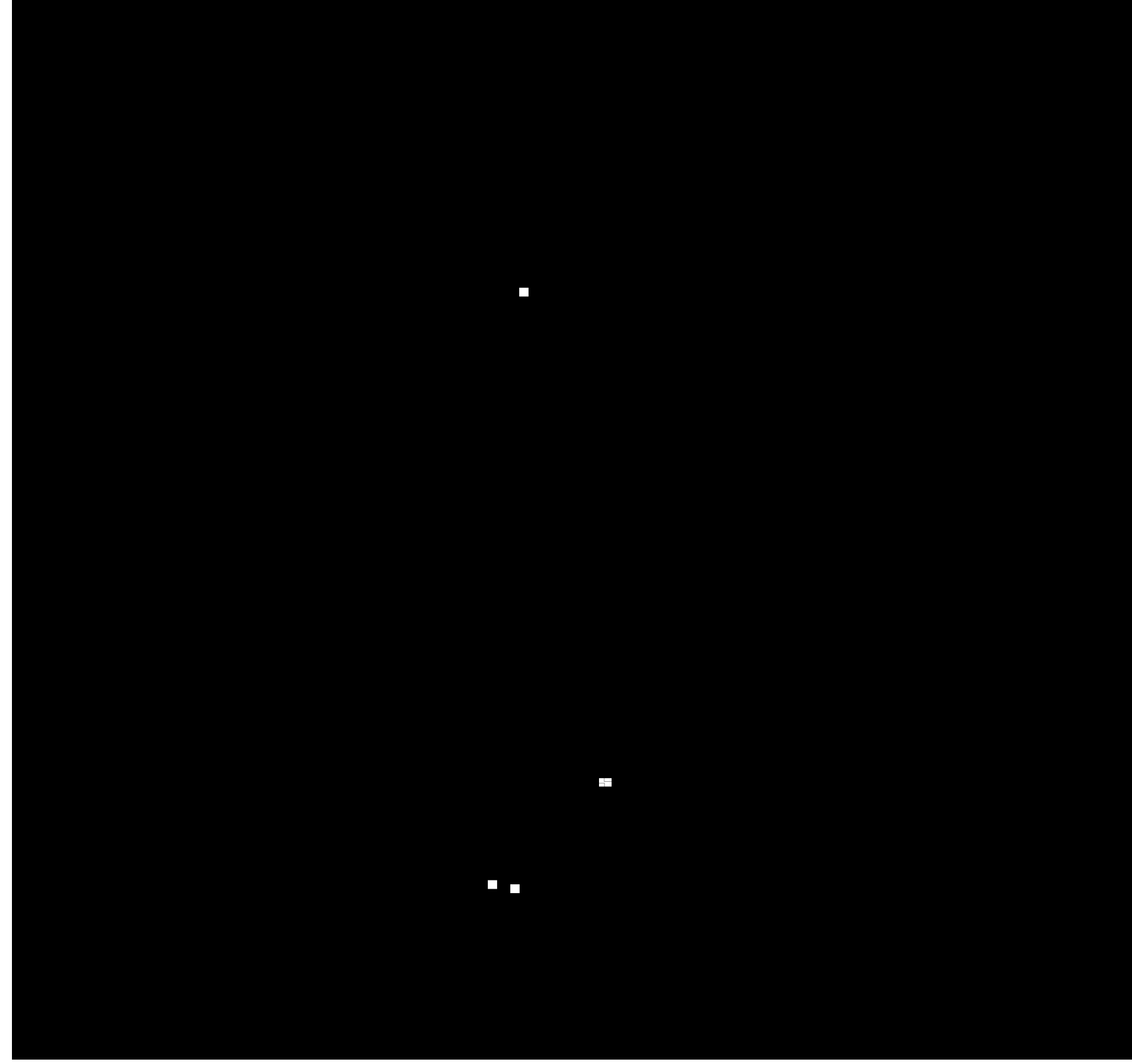


(A) Solute concentration ratios in A0

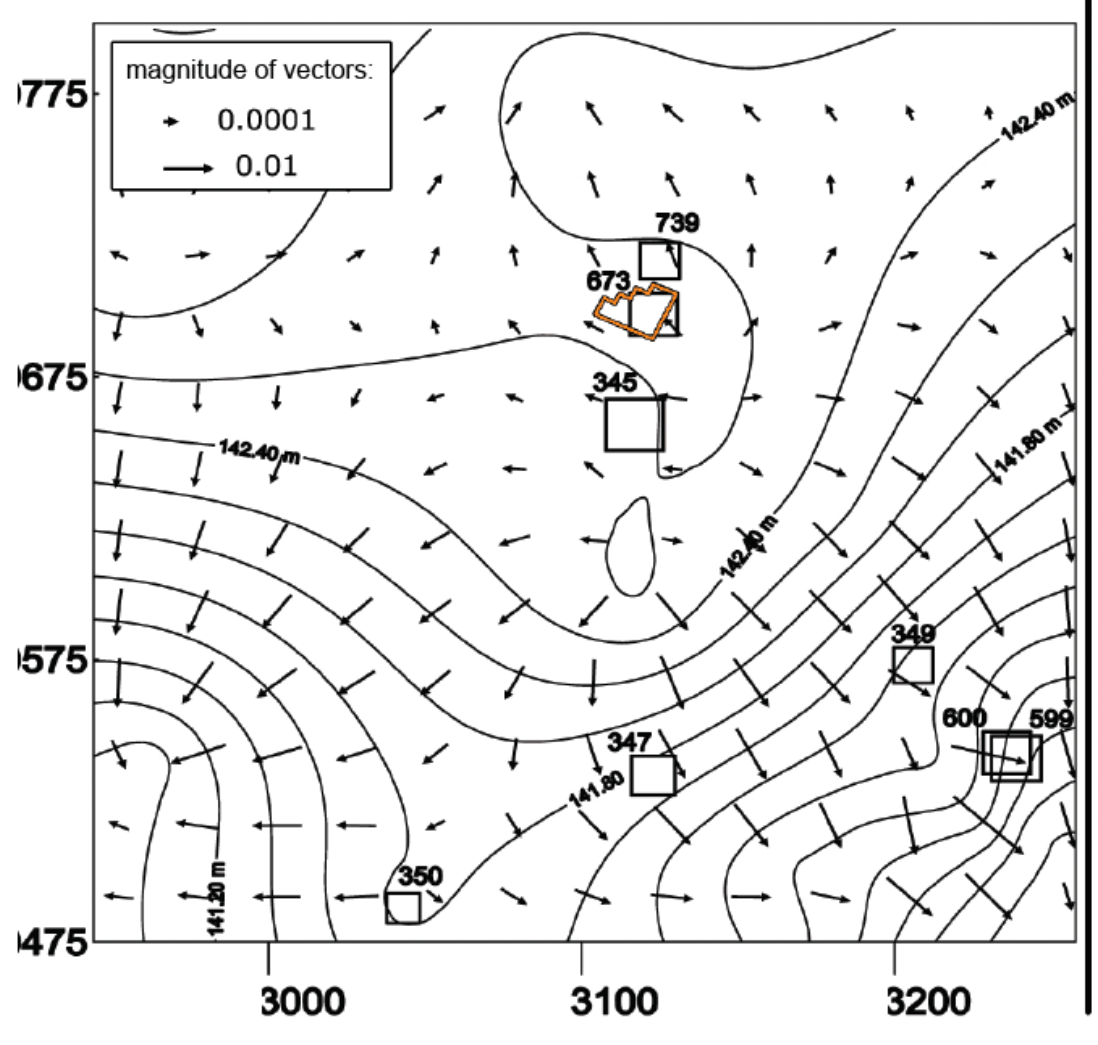

(B) Solute concentration ratios in A1

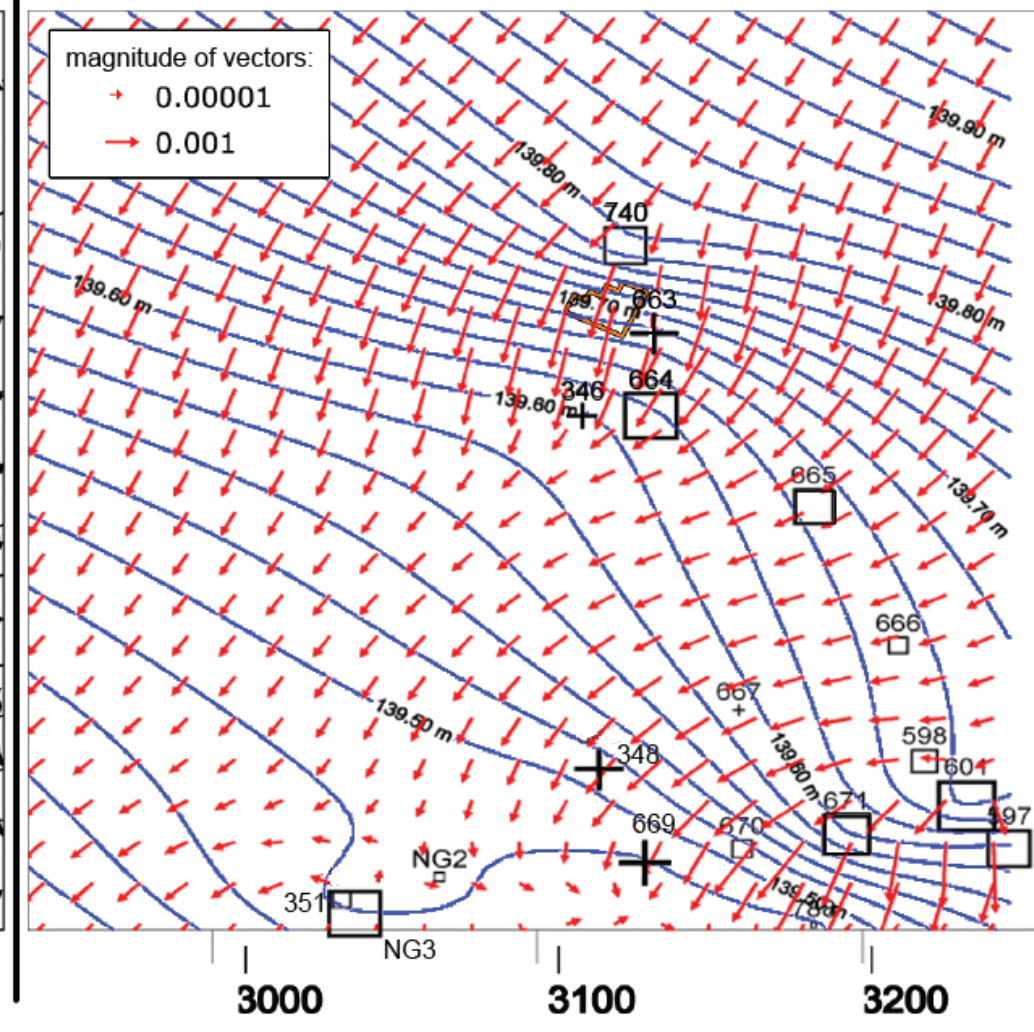

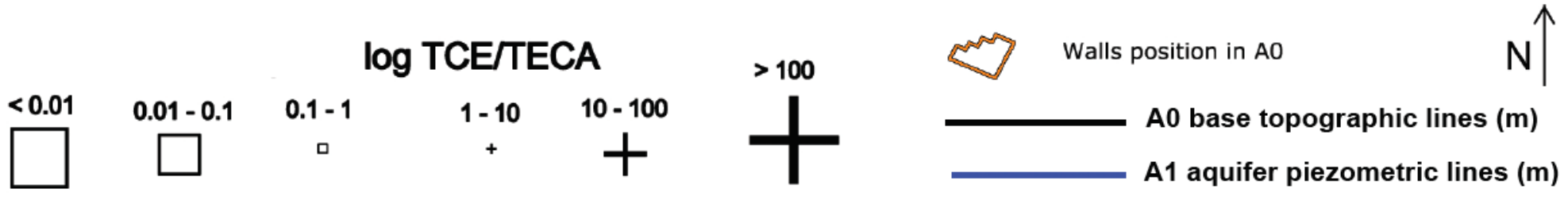




\section{(A) considering source inside encapsulated zone}

\section{AO}

A1

(B) considering source inside encapsulated zone and along the steepest portion of the aquitard surface

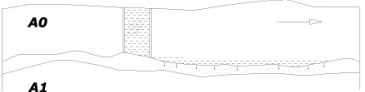

(B1) without active pumping well

\section{$\uparrow_{\mathrm{N}}$}

$\stackrel{25 \mathrm{~m}}{\stackrel{7}{2}}$

LEGEND

D-type borchol
aquifer ( $A 1$ )

Active wells in $\mathrm{A1}$
aquifer from 2006 to
2008

$774^{\circ} / 78$

Mg: par macan

Partice linepath
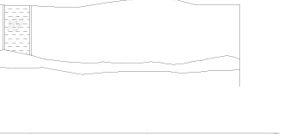

Rho

Industria

Area
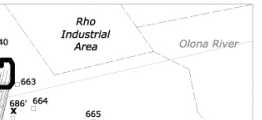

$x^{696} 654$

665

666

667

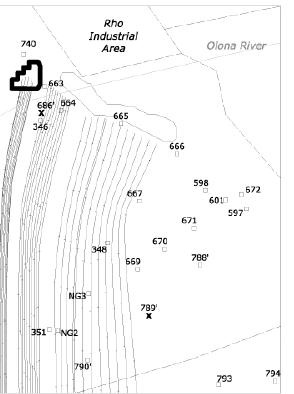

$\uparrow_{N}$
Encaspulated

source

Hypothesis of

contaminant

location

Qualitative

distribution of

DNAPLs outside

Starting position of

particle cloud

during simulations
(B2) with active pumping well

$\uparrow_{N}$

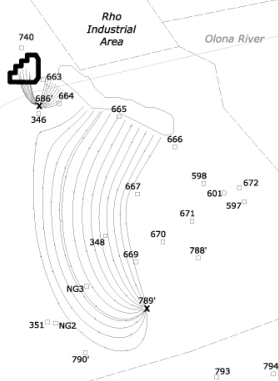




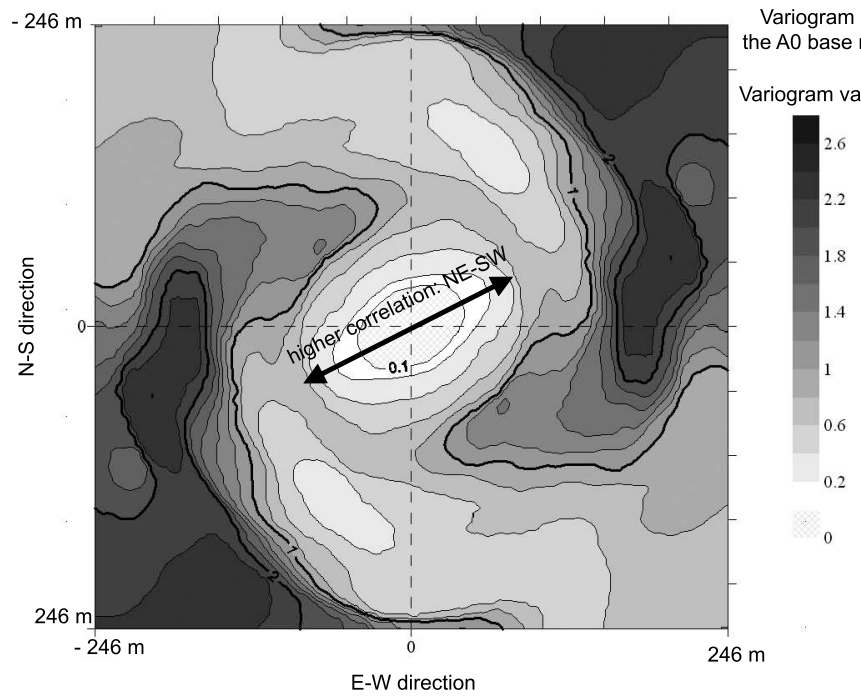




\section{NG1 borehole}

grain size obtained after

sieving on soil samples (\%) soil

sampling

location total and relative content of chlorinated solvents compunds ( $\mathrm{mg}$ per $\mathrm{kg}$ of soil sampled)

OC $=$ other coumpunds
Legend (USCA classification)

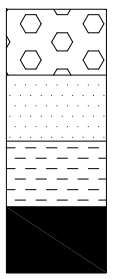

Gravel

Sand

Silt

Clay

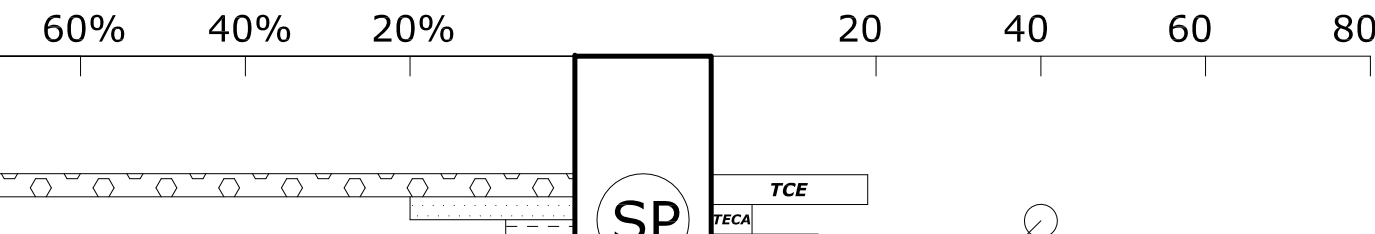

depth from ground

$5 m$

$10 m$

$15 m$

$20 m$

$25 m$

$30 m$

$35 m$

SP

TCE

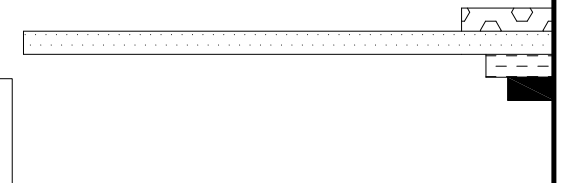

SP

TCE

OC

\begin{tabular}{|l|l|}
\multicolumn{2}{|c|}{ TECA } \\
\hline OC \\
\hline
\end{tabular}

SP

$45 m$ 